\title{
The Expanding Family of Bone Marrow Homing Factors for Hematopoietic Stem Cells: Stromal Derived Factor 1 Is Not the Only Player in the Game
}

\author{
Mariusz Z. Ratajczak, ${ }^{1,2}$ ChiHwa Kim, ${ }^{1}$ Anna Janowska-Wieczorek, ${ }^{3}$ and Janina Ratajczak1 \\ ${ }^{1}$ Stem Cell Biology Program at the James Graham Brown Cancer Center, University of Louisville, Louisville, KY 40202, USA \\ ${ }^{2}$ Department of Physiology, Pomeranian Medical University, 70-111 Szczecin, Poland \\ ${ }^{3}$ Department of Medicine, University of Alberta, Edmonton, AB, Canada T6G $2 G 3$
}

Correspondence should be addressed to Mariusz Z. Ratajczak, mzrata01@louisville.edu

Received 28 February 2012; Accepted 29 March 2012

Academic Editors: A. Aronheim, L. Berghella, M. Bouche, R. D. Byrne, and S. Mañes

Copyright ( 2012 Mariusz Z. Ratajczak et al. This is an open access article distributed under the Creative Commons Attribution License, which permits unrestricted use, distribution, and reproduction in any medium, provided the original work is properly cited.

\begin{abstract}
The $\alpha$-chemokine stromal derived factor 1 (SDF-1), which binds to the CXCR4 and CXCR7 receptors, directs migration and homing of CXCR4 ${ }^{+}$hematopoietic stem/progenitor cells (HSPCs) to bone marrow (BM) and plays a crucial role in retention of these cells in stem cell niches. However, this unique role of SDF-1 has been recently challenged by several observations supporting SDF-1-CXCR4-independent BM homing. Specifically, it has been demonstrated that HSPCs respond robustly to some bioactive lipids, such as sphingosine-1-phosphate (S1P) and ceramide-1-phosphate (C1P), and migrate in response to gradients of certain extracellular nucleotides, including uridine triphosphate (UTP) and adenosine triphosphate (ATP). Moreover, the responsiveness of HSPCs to an SDF-1 gradient is enhanced by some elements of innate immunity (e.g., C3 complement cascade cleavage fragments and antimicrobial cationic peptides, such as cathelicidin/LL-37 or $\beta 2$-defensin) as well as prostaglandin E2 (PGE2). Since all these factors are upregulated in $\mathrm{BM}$ after myeloblative conditioning for transplantation, a more complex picture of homing emerges that involves several factors supporting, and in some situations even replacing, the SDF-1-CXCR4 axis.
\end{abstract}

\section{Introduction}

The $\alpha$-chemokine stromal derived factor 1 (SDF-1), which binds to the seven-transmembrane-spanning $G_{\alpha I}$ proteincoupled receptor CXCR4 is, as has been demonstrated by several investigators, unique among the family of chemokines, because it directly chemottracts hematopoietic stem/ progenitor cells (HSPCs) [1-3]. Since CXCR4 is expressed on both long- and short-term repopulating hematopoietic stem cells (HSCs), as well as hematopoietic progenitors, SDF1 plays an important role in regulating trafficking of these cells and their homing after transplantation to BM, and is later involved in their active retention in BM stem cell niches [2-5].

However, while a role for the SDF-1-CXCR4 axis in retention of HSPCs in BM under steady-state conditions is undisputed, its exclusive role in stem cell homing has been challenged by several observations that support the existence of SDF-1-CXCR4-independent homing [6-8]. In particular, it has been reported that; (i) CXCR4 $4^{-/}$fetal liver HSPCs home to BM in an SDF-1-independent manner [6], (ii) homing of murine HSPCs made refractory to SDF-1 by incubation and coinjection with a CXCR4 receptor antagonist (AMD3100) is normal or only mildly reduced [7], (iii) HSPCs in which CXCR4 has been knocked down by means of an SDF-1 intrakine strategy are able to engraft [8], and finally (iv) myeloablative conditioning for transplantation induces a highly proteolytic microenvironment in BM that leads to proteolytic degradation of SDF-1, and thus may severely attenuate its chemotactic gradient [9].

All this evidence strongly suggests the involvement of other factors that support homing of HSPCs. In this paper, we will present cumulative evidence that gradients of the bioactive sphingophospholipids, such as sphingosine-1phosphate (S1P) [10-12] and ceramide-1-phosphate (C1P) 
$[9,13,14]$, which are products of membrane lipid metabolism, as well as some extracellular nucleotides, including uridine triphosphate (UTP) and adenosine triphosphate (ATP) [15-17], play an important role as homing factors for HSPCs, in addition to SDF-1.

Besides these novel, still underappreciated, homing factors, several mediators are upregulated in BM conditioned for transplantation that may positively enhance (prime) the responsiveness of CXCR $4^{+}$HSPCs to an SDF-1 gradient [18, 19]. This is biologically significant because, as mentioned previously, myeloablative conditioning for transplantation induces a highly proteolytic microenvironment in BM that leads to proteolytic degradation of SDF-1 and attenuates its chemotactic gradient [9]. Therefore, all these SDF-1CXCR4 axis-sensitizing factors counteract a decrease in the active SDF-1 gradient. These important priming factors or modulators of the SDF-1-CXCR4 axis include elements of innate immunity, such as cleavage fragments of the third component (C3) of the complement cascade (CC), antimicrobial cationic peptides, such as cathelicidin (LL-37) and $\beta 2$-defensin, and the eicosanoid prostaglandin E2 (PGE2) [18-23]. While C3 cleavage fragments (short-lived C3a and its long-lived derivative desArg C3a), LL-37, and $\beta 2$-defensin increase the chemotactic responsiveness of HSPCs to very shallow SDF-1 gradients by promoting incorporation of the CXCR4 receptor into membrane lipid rafts, which are necessary for optimal activation of this receptor $[18,19]$, PGE2 upregulates the expression level of this receptor on HSPCs $[22,24]$. In both of these situations, the CXCR4 ${ }^{+}$ HSPCs are able to respond more robustly to SDF-1.

The mechanisms that govern homing of HSPCs to BM have been the subject of several recent reviews [3, 23-27]. However, here we will focus on novel factors that play a role in SDF-1-independent BM homing as well as factors that modulate the activity of the SDF-1-CXCR4 axis and are involved in homing of HSPCs. What is most important, all of these factors become upregulated in BM conditioned for transplantation. Thus, the existence of these factors provides a novel and complex picture of the homing process that will be presented and discussed in more detail herein. Figure 1 shows a novel view of HSPC homing in response to SDF-1 and all other chemoattractants involved in this process as well as the involvement of the SDF-1-CXCR4 axis priming factors.

\section{The Role of SDF-1 in Developmental Migration of HSPCs and in Adult Hematopoiesis}

HSPCs migrate during embryonal development, colonizing different organs where hematopoiesis is initiated. First, definitive HSPCs are identified in the so-called aortagonado-mesonephros (AGM) region, and in the second trimester of gestation they colonize fetal liver, which is a major hematopoietic organ at this stage of development [2832]. Subsequently, at the beginning of the third trimester of gestation, HSPCs leave the fetal liver and colonize the

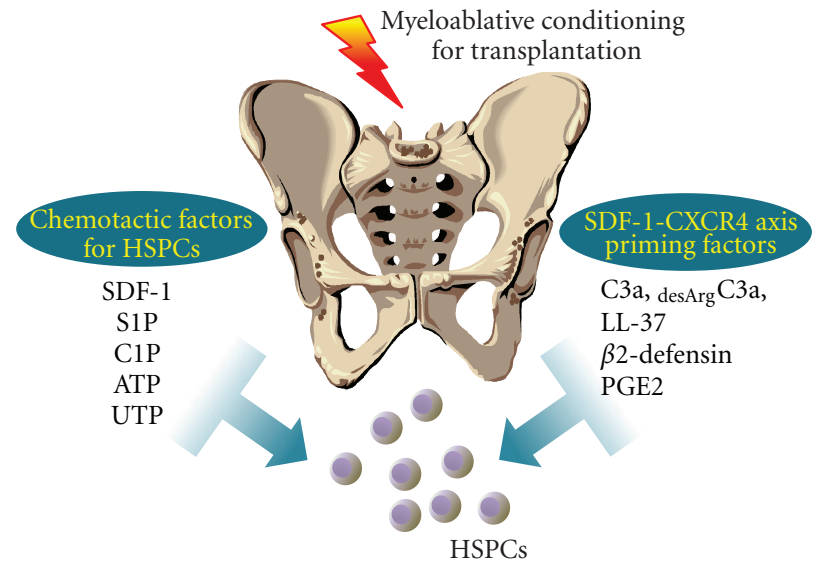

Figure 1: Homing of HSPCs to BM-the involvement of new chemotactic and priming factors. Evidence has accumulated that HSPCs home to BM in response not only to SDF-1 but also in response to some bioactive lipids ( $\mathrm{S} 1 \mathrm{P}$ and $\mathrm{C} 1 \mathrm{P}$ ), as well as extracellular nucleotides (ATP and UTP). The responsiveness of HSPCs to an SDF-1 gradient is also positively modulated by several priming molecules, including peptides of the cationic antimicrobial peptide (CAMPs) family, and PGE2.

developing BM, which will become a major hematopoietic organ for the rest of mammalian life $[33,34]$.

The role of SDF-1 in developmental colonization of the BM microenvironment was convincingly demonstrated in SDF-1 and CXCR4 knockout animals [6, 35, 36]. These studies revealed that murine embryos that lack SDF-1 or CXCR4 display defects in BM development [36], as well as other defects in heart, brain, and large-vessel development that contribute to their lethal phenotype [37-40], and die in utero. However, except for a defect in B-lymphocyte lineage development, they have normal fetal liver hematopoiesis [36-40].

These studies on SDF-1 ${ }^{-/-}$and $\mathrm{CXCR} 4^{-/-}$embryos revealed two important points. First, colonization of fetal liver during embryogenesis by AGM-derived HSPCs is not governed by the SDF-1-CXCR4 axis, and second, SDF-1 is required for proper migration of HSPCs from fetal liver to BM. The fact that murine embryos with CXCR4- or SDF1 -deficiency have a normal number of myeloid HSPCs in fetal liver [6, 37-43], which is colonized by HSPCs migrating from the AGM region, suggests that this process is mediated by other chemoattractants. Taking into consideration the important role of S1P in the development of several tissues during embryogenesis $[44,45]$, it is likely that S1P compensates for the SDF-1-CXCR4 deficiency in these animals during developmental migration of HSPCs. This, however, needs further study. It is also obvious that at some point in development, HSPCs increase their dependence on SDF-1mediated chemotaxis.

Interestingly, as mentioned previously, fetal liver-derived $\mathrm{CXCR}^{-/-}$cells may still engraft in lethally irradiated mice and radioprotect these animals $[1,42,46]$. However, it has been demonstrated that irradiation chimeras created with $\mathrm{CXCR}^{-/-}$HSPCs display some defects in expansion and 
retention of HSPCs in BM [42]. This fact pinpoints the requirement of the SDF-1-CXCR4 axis not only in retention of HSPCs in BM but also in proper adult hematopoiesis and maintenance of a quiescent HSC pool $[42,46]$. In this process, the SDF-1-CXCR4 axis plays a crucial role, together with other factors, such as Very Late Antigen-4 (VLA-4, also known as $\alpha_{1} \beta_{4}$ integrin), expressed on HSPCs, and Vascular Adhesion Molecule 1 (VCAM-1, also known as CD106) expressed in the BM niche [47-49].

SDF-1 has been reported as being expressed in both osteoblastic and endothelial stem cell niches by osteoblasts and endothelial cells, respectively $[25,50]$. In support of this finding, morphological studies revealed that HSCs are found in the BM microenvironment in contact with the cells expressing high amounts of SDF-1, which are called CXCL12-(another name for SDF-1) abundant reticular (CAR) cells. In particular, CAR cells surround sinusoidal endothelial cells and are located near the endosteum as part of the endothelial and osteoblastic niches, respectively $[50,51]$. SDF- 1 is also secreted by BM stromal cells, including nestin $^{+}$cells $[51,52]$.

Expression of SDF-1 is regulated at the transcriptional level by hypoxia-inducible factor 1 alpha (HIF-1 $\alpha$ ), which is upregulated in $\mathrm{BM}$ conditioned for transplantation in response to myeloablative treatment [53]. Nevertheless, despite upregulation of SDF-1 expression at the mRNA level, the chemotactic gradient of SDF-1 protein in BM may be attenuated by several proteolytic enzymes, whose expression is induced in $\mathrm{BM}$ after myeloablative conditioning for transplantation [9]. To ameliorate this effect, several mechanisms have been identified that compensate for a decrease in the SDF-1 gradient, which will be discussed in the following section.

\section{Priming Factors That Responsiveness of CXCR4 $^{+}$HSPCs to an SDF-1 Gradient}

As mentioned previously, the biological activity of SDF1 decreases in $\mathrm{BM}$ due to the induction of a proteolytic microenvironment after conditioning for transplantation, as seen, for example, after lethal irradiation [9]. In an elegant study, it has been shown that a few amino acids located at the $\mathrm{N}$-terminus of SDF-1 that are crucial for the biological activity of this peptide may be removed by metalloproteinase2 (MMP-2) or MMP-9 [54]. This proteolytic processing of SDF-1 completely inhibits its chemotactic properties [9]. However, as shown in Figure 1, at the same time several factors have been reported to enhance or sensitize the responsiveness of HSPCs to an SDF-1 gradient. These factors include elements of innate immunity, such as cleavage fragments of C3 [18], cationic antimicrobial peptides, such as cathelicidin (LL-37) and $\beta 2$-defensin [19-21], and prostaglandin E2 (PGE2) [22-24], a member of the eicosanoid family.

This priming effect can easily be evaluated in vitro in the transwell migration assay, where two chambers (an upper chamber containing the tested cells and a lower chamber containing chemoattractant) are separated by a porous membrane that allows transmigration of cells that respond to the chemotactic gradient (Figure 2). Cells that respond to this gradient migrate and subsequently accumulate in the lower chamber. Figures 2 and 3 demonstrate that the chemotaxis of HSPCs to a shallow SDF-1 gradient may be significantly enhanced in the presence of cationic antimicrobial peptides (CAMPs) [20,55]. The role of these priming factors in modulating the SDF-1-CXCR4 axis will be discussed hereinafter.

3.1. C3 Cleavage Fragments. It has been demonstrated that the CC, as an evolutionarily old danger-sensing mechanism, becomes activated during conditioning for transplantation by radio- and chemotherapy [9]. The third component of the CC (C3) is an abundant protein in PB plasma $(1 \mathrm{mg} / \mathrm{mL})$ and becomes cleaved during CC activation by both classical and alternative pathways [56]. The C3 cleavage leads to release of liquid-phase cleavage fragments, the $\mathrm{C} 3 \mathrm{a}$ and des- $\mathrm{Arg} \mathrm{C} 3 \mathrm{a}$ anaphylatoxins [57]. Liquid-phase anaphylatoxin $\mathrm{C} 3 \mathrm{a}$ has a short half-life in plasma and is processed by serum carboxypeptidase $\mathrm{N}$ to des- $\mathrm{Arg} \mathrm{C} 3 \mathrm{a}$, which is a long-half-life cleavage product.

Previous work on $\mathrm{C}^{-/-}$mice revealed that these animals are hematologically normal under steady-state conditions and display a significant delay in hematopoietic recovery from either irradiation or transplantation of wild type (WT) HSPCs [55, 58, 59]. Specifically, transplantation of histocompatible wild type (WT) Sca- $1^{+}$cells into $\mathrm{C}^{-1-}$ mice resulted in (i) a decrease in day 12 colony forming units in spleen (CFU-S), (ii) a 5-7-day delay in platelet and leukocyte recovery, and (iii) a reduced number of BM hematopoietic clonogenic progenitors at day 16 after transplantation. The fact that HSPCs from $\mathrm{C}^{-/-}$mice engrafted normally into irradiated WT mice suggests that there was a defect in the hematopoietic environment of $\mathrm{C}^{-/-}$mice and not some intrinsic defect of $\mathrm{C}^{-/-}$mouse-derived HSPCs $[18,58]$.

Since $\mathrm{C}^{-/-}$mice cannot activate/cleave $\mathrm{C} 3$, the $\mathrm{C} 3$ fragments C3a and des- $\mathrm{Arg}_{\mathrm{C} g} \mathrm{C}$ a were examined for a role in HSPC engraftment, and we found that $\mathrm{C} 3 \mathrm{a}$ and ${ }_{\mathrm{des}-\mathrm{Arg}} \mathrm{C} 3 \mathrm{a}$ increase CXCR4 incorporation into membrane lipid rafts, thus potentiating HSPC responsiveness to SDF-1 gradients $[59,60]$.

Lipid rafts are membrane domains rich in sphingolipids and cholesterol, which form a lateral assembly in a saturated glycerophospholipid environment. The raft domains are known to serve as moving platforms on the cell surface and are more ordered and resistant to nonionic detergents than other areas of the membrane [61]. These domains are also good sites for crosstalk between various cellular signaling proteins. For example, it has recently been reported that small guanine nucleotide triphosphatases (GTPases), such as Rac-1 and Rac-2, which are crucial for engraftment of hematopoietic cells after transplantation, are associated with lipid rafts on migrating HSPCs [62-64]. Therefore, since the CXCR4 receptor is a lipid raft-associated protein, its signaling ability is enhanced if it is incorporated into membrane lipid rafts, where it can better interact with several signaling molecules, including the small GTPase Rac-1. This colocalization of CXCR4 and Rac-1 in lipid rafts facilitates GTP binding and activation of Rac-1 [62, 65-67]. Thus, the generation of $\mathrm{C} 3$ cleavage fragments in the $\mathrm{BM}$ microenvironment 


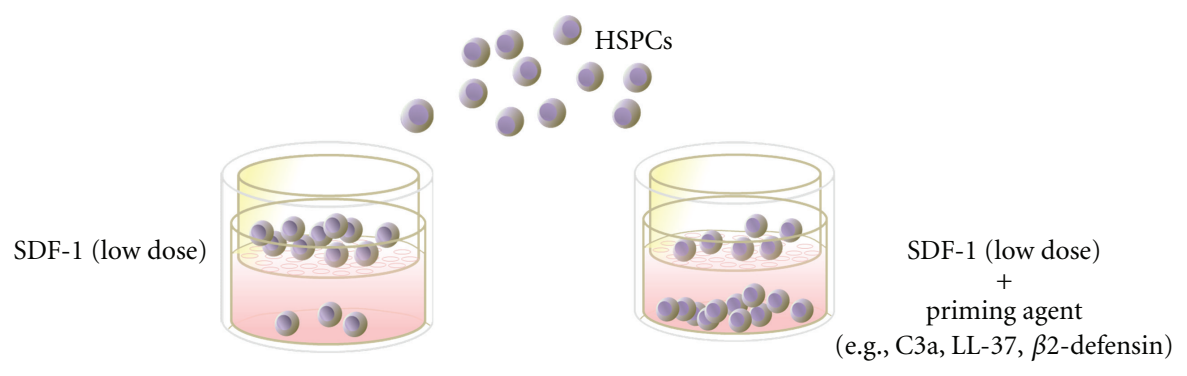

(a)
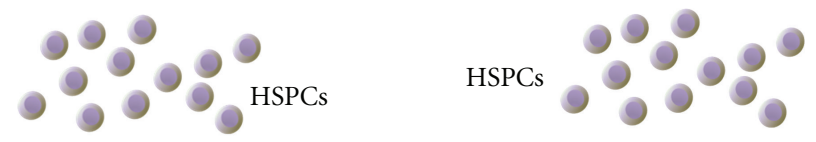

Ex vivo priming by CAMP

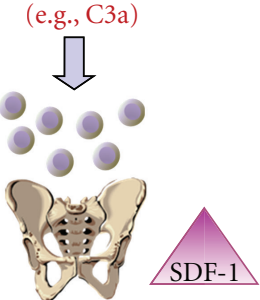

(b)

FIGURE 2: A priming effect increases the responsiveness of HSPCs to shallow SDF-1 gradients. The overall scheme of chemotactic assays performed in the transwell system to evaluate the HSPC priming phenomenon (a). In the presence of a priming agent (e.g., cationic antimicrobial peptides (CAMPs), such as C3a or cathelicidin (LL-37) or $\beta 2$-defensin), HSPCs respond more robustly to low doses of SDF-1 $[20,55]$. This phenomenon is currently being tested in the clinic, where UCBs are exposed ex vivo to a priming agent (C3a) before transplantation (b).

may somehow act as a mechanism that increases the responsiveness of HSPCs to an SDF-1 gradient when it is degraded by a proteolytic microenvironment [18]. In C3-deficient mice this phenomenon is attenuated, explaining why these animals show delayed engraftment. In this context, increases in C3a or desArg C3a levels in BM after myeloablative conditioning [18] can be envisioned as one of the mechanisms that promote homing of HSPCs (Figures 1-3).

3.2. Cationic Antimicrobial Peptides (CAMPs). CAMPs are host-defense peptides and are an evolutionarily conserved component of the innate immune response [68-71]. CAMPs have been demonstrated to kill bacteria, enveloped viruses, fungi, and even transformed or cancerous cells but affect only the organization and not the viability of the eukaryotic cell membrane. The selective effects of CAMPs (e.g., eukaryotic membrane perturbation and prokaryotic killing) are known to be dependent on characteristics of cell membranes [21, 68-71]. Prokaryote cell membranes are susceptible to strong electrostatic and hydrophobic interactions with these natural antibiotics. In contrast, cell membranes of eukaryotic cells, because of high cholesterol content and weak hydrophobic interactions with cationic peptides, are more resistant to the potentially toxic effects of these peptides. One of the properties of CAMPs that we identified is their ability to enhance or prime the responsiveness of cells to an SDF-1 gradient. Interestingly, the $\mathrm{C} 3 \mathrm{a}$ and ${ }_{\operatorname{des} A r g} \mathrm{C} 3 \mathrm{a}$ anaphylatoxins mentioned previously share several properties with CAMPs [72].

Cathelicidin (LL-37) and $\beta 2$-defensin belong to the CAMP family and like $\mathrm{C} 3 \mathrm{a}$, as mentioned before, increase (positively prime) the responsiveness of HSPCs to an SDF1 homing gradient (Figure 1). The molecular explanation of this phenomenon is the same as in the case of C3a: CAMPs promote the incorporation of CXCR4 into membrane lipid rafts $[59,60]$. Since, as mentioned before, membrane lipid rafts assemble together several signaling molecules, incorporation of CXCR4 into lipid rafts facilitates signaling, and thus CXCR4 is activated more efficiently in the presence of low doses of SDF-1.

Further studies are needed to see whether, in addition to CXCR4, receptors for other chemoattractants of HSPCs that we will discuss hereinafter, such as S1P, C1P, ATP, and UTP, are also lipid raft-regulated and whether CAMPs enhance their incorporation into membrane lipid rafts. Of note, it has been reported that stimulation of $\mathrm{S} 1 \mathrm{P}$ receptor type $1\left(\mathrm{~S}_{\mathrm{P}} \mathrm{P}_{1}\right)$ by its agonist, FY720, increases the responsiveness of HSPCs to an SDF-1 gradient [73]. However, this phenomenon probably occurs because of intercellular crosstalk between CXCR4 and $\mathrm{S}_{1} \mathrm{P}_{1}$. Since a receptor for another bioactive lipid, C1P, has not yet been identified, it is not clear whether $\mathrm{C} 1 \mathrm{P}$ signaling is also lipid raft-regulated. However, data indicate that this receptor is expressed on HSPCs and is sensitive to pertussis toxin, which suggests that, like S1P, it is 


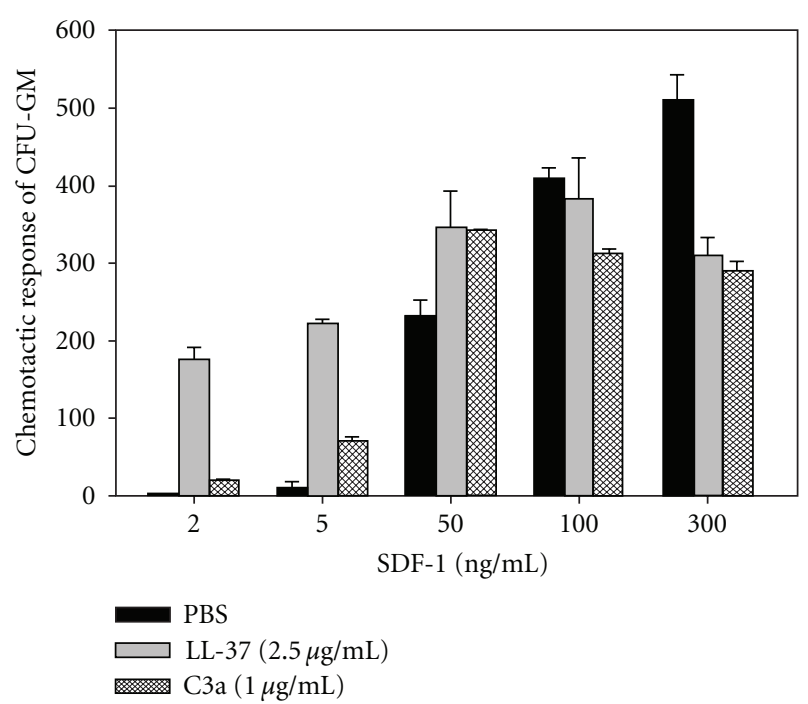

Figure 3: Cationic antimicrobial peptides (CAMPs) C3a and LL37 enhance the responsiveness of murine BM- and human UCBderived HSPCs to an SDF-1 gradient: Chemotaxis of murine BM CFU-GM in response to different concentrations of SDF-1 with and without C3a or LL-37 [20,55]. Values are the fold increase in the number of migrated cells compared to the number of migrated cells in medium alone. Gray bars indicate the presence of LL-37 $(2.5 \mu \mathrm{g} / \mathrm{mL})$, cross-hatched bars the presence of C3a $(1 \mu \mathrm{g} / \mathrm{mL})$ in the lower transwell chambers, and black bars indicate PBS only. The data represent the combined results from three independent experiments performed in duplicate per group $(n=6)$.

a $G_{\alpha \mathrm{i}}$ protein-coupled receptor [9]. Also, purinergic receptors for ATP and UTP are $\mathrm{G}_{\alpha \mathrm{i}}$ protein-coupled receptors, and the possibility of modulation of the activity of these receptors by C3a, LL-37, or $\beta 2$-defesin requires further study.

3.3. Prostaglandin E2. In addition to cationic peptides, prostaglandin E2 (PGE2) has also been purported to increase the responsiveness of HSPCs to an SDF-1 gradient [22, 23]. The mechanism of PGE2 influence on this process, however, is not lipid raft dependent. As previously reported, PGE2 plays an important role in homing of HSPCs by upregulating the expression of CXCR4 on the surface of HSPCs, and this seems to be the most likely mechanism responsible for increasing chemotaxis in response to an SDF-1 gradient after pretreatment of HSPCs by PGE2 [22-24, 74]. In further support of a role for PGE2 in homing, it has recently been reported that the level of this eicosanoid is significantly upregulated in BM conditioned for hematopoietic transplantation by lethal irradiation [9].

In addition to the CAMPs and PGE2, hyaluronic acid [75] and thrombin [76] have also been reported to increase the responsiveness of HSPCs to an SDF-1 gradient. The exact mechanism of this priming effect, however, has still not been elucidated but is most likely mediated by the interaction of hyaluronic acid with integrin receptors on HSPCs that are present in lipid rafts. This possibility, however, needs further study.

\section{The Bioactive Sphingolipids S1P and C1P as Novel BM Homing Factors}

Sphingophospholipids are important components of cell membranes and are derived from the aliphatic amino alcohol sphingosine and its acylated derivative ceramide [27, 7779]. Both sphingosine and ceramide are precursors for the bioactive derivatives sphingosine-1-phosphate (S1P) and ceramide-1-phosphate (C1P), which strongly chemoattract HSPCs [9].

$\mathrm{S} 1 \mathrm{P}$ is a product of two sphingosine kinases (SK1 and SK2), is released from cells by a transporter-facilitated process, and interacts with at least five $G_{\alpha i}, G_{12 / 13}$, and $G_{q}$ protein-coupled seven-transmembrane-spanning receptors, $\mathrm{S}_{1} \mathrm{P}_{1-5}$, on the surface of target cells $[80,81]$. While $\mathrm{S}_{1} \mathrm{P}_{1}$ and $\mathrm{S}_{1} \mathrm{P}_{3}$ receptors are most important in promoting the migration of HSPCs, $\mathrm{S}_{1} \mathrm{P}_{2}$ may have an opposing function [82-84]. Of note, $\mathrm{S}_{1} \mathrm{P}_{1-5}$ receptors are rapidly internalized from the cell surface after binding S1P, which is similar to the internalization of CXCR4 after binding SDF-1. Accordingly, $\mathrm{S} 1 \mathrm{P}$ has been identified as a chemottractant for hematopoietic progenitor cells $[11,12,56]$, a regulator of trafficking of T lymphocytes between lymphoid organs and PB [85-87], a factor involved in egress of early B-lymphoid cell progenitors from $\mathrm{BM}[88,89]$, and a regulator in the trafficking of myeloid progenitors between BM and peripheral organs [89]. We and others have recently demonstrated that S1P plays a pivotal role in pharmacological mobilization and egress of HSPCs from BM into peripheral blood (PB) $[12,90]$ and since it is unregulated in $\mathrm{BM}$ conditioned for transplantation may also probably chemoattract HSPCs to BM [9].

Another bioactive sphingolipid, C1P, is structurally related to S1P and can be generated by phosphorylation of ceramide ( $\mathrm{N}$-acyl sphingosine) by ceramide kinase (CERK) [91]. Unlike ceramide (which is often proapoptotic), C1P has been reported to promote cell growth, survival, and migration through an unknown receptor-initiated signaling pathway that is pertussis toxin-sensitive and therefore likely to involve a $G_{\alpha i}$ protein-coupled seven-transmembranespanning receptor $[14,92]$. The receptors for $\mathrm{C} 1 \mathrm{P}$, however, have not yet been identified, though they are clearly distinct from the known S1P receptors. C1P was initially identified as a chemottractant for monocytes [13] and, as has recently been demonstrated, is also an important, novel, and potent chemotactic factor involved in the homing of HSPCs to BM [9].

There are some obvious differences in biological availability between these bioactive lipids. While S1P is released from cells as an important signaling molecule and in $\mathrm{PB}$ is transported by erythrocytes, platelets, albumin, and high density lipoproteins (HDL), C1P is an intracellular second messenger released from leaky damaged cells and is also abundant in plasma in the HDL fraction [14]. While considering chemotactic gradients of S1P and C1P, one has to remember that both bioactive lipids must be present in biological fluids as free, unbound molecules in order to have a chemotactic potential [9].

Importantly, both S1P and C1P are upregulated in the $\mathrm{BM}$ microenvironment after myeloablative conditioning of 

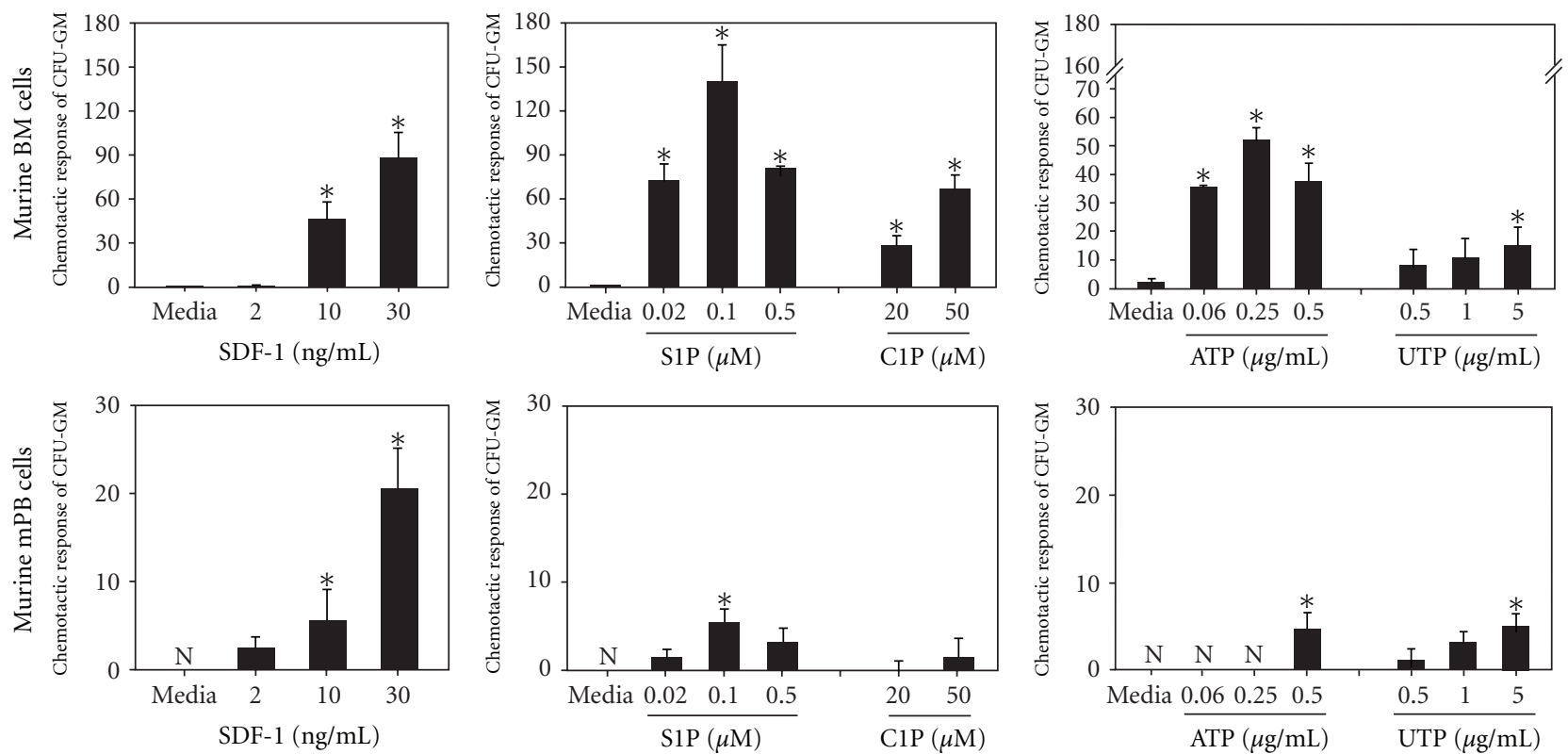

FIGURE 4: Responsiveness of murine bone marrow-(BM-) and mobilized peripheral blood-(mPB-) derived HSPCs to SDF-1, S1P, C1P, ATP, and UTP gradients. The difference in responsiveness of HSPCs isolated from BM versus mPB could be explained by a fact that HSPCs in mPB are exposed to high concentration of bioactive lipids and extracellular nucleotides, which may lead to downregulation or desensitization of appropriate receptors. After internalizing these receptors, HSPCs need some time to reexpress functional receptors on the cell surface to recover their responsiveness to these chemoattractants (data not published, $P<0.01$ ).

BM for transplantation [9]. For example, our recent mass spectrometry (MS) analysis revealed that the major isoforms of $\mathrm{C} 1 \mathrm{P}$ and S1P were detected at higher concentrations in supernatants harvested from irradiated BM. Taken together with their potent chemotactic effects, these changes in concentration of bioactive lipids in BM after myeloablative conditioning for transplantation suggest that these factors play an important role in the homing process for HSPCs [9].

However, both bioactive lipids have a limited half-life, with S1P degraded by several enzymes, such as S1P lyase (SPL), lipid phosphate phosphatases (LPP1-3), and S1Pspecific phosphatases (SPP1 and SPP2), while C1P is degraded by LPP1-3 [93-101]. These pathways may terminate the effects of S1P and C1P on HSPC migration. Therefore, further studies are needed to evaluate the changes in kinetics of the response to $\mathrm{S} 1 \mathrm{P}$ and $\mathrm{C} 1 \mathrm{P}$ gradients in $\mathrm{BM}$ after myeloablative treatment.

Furthermore, as mentioned previously, $\mathrm{S}_{1} \mathrm{P}_{1-5}$ receptors and, most likely, still-unknown C1P receptors are downregulated on the surface of HSPCs in the presence of S1P and C1P, respectively [27]. This may explain why HSPCs harvested from $\mathrm{mPB}$ previously exposed to high S1P plasma concentrations do not respond robustly to S1P and C1P gradients compared to BM-derived HSPCs (Figure 4). After internalizing S1P receptors, HSPCs need some time to reexpress functional receptors on the cell surface to recover their responsiveness [27].

Finally, in addition to S1P and C1P, we tested other bioactive lipids. We observed that, in contrast to S1P and $\mathrm{C} 1 \mathrm{P}$, other members of the bioactive lipid family, such as lysophosphatidic acid (LPA) and lysophosphatidylcholine
(LPC), do not show chemotactic activity against HSPCs. Thus, S1P and C1P seem to play a unique role among evaluated so far members of the family of bioactive lipids.

\section{Purinergic Nucleotides as Underappreciated Homing Factors}

Evidence has accumulated that extracellular-secreted $5^{\prime}$ nucleotide triphosphates (ATP and UTP) are important biological mediators involved in cell proliferation, survival, and cell trafficking $[102,103]$. In one elegant work, it was shown that ATP and UTP stimulate, in synergy with some cytokines, expansion of HSCs that repopulate BM after transplantation in an immunodeficient mouse model [16]. These nucleotides have also been described as chemotactic factors in several types of cells, including granulocytes and monocytes [15$17,104]$. Significantly, as recently demonstrated for UTP and to a lesser extent ATP, they modulate trafficking of HSCs and their homing to BM niches [16]. Thus, extracellular nucleotides may provide a powerful tool to modulate the function of HSPCs. Interestingly, they display the opposite effects on human acute myeloblastic leukemia cells to that which is observed for normal HSCs [105], by inhibiting proliferation, migration, and engraftment of these cells in immunodeficient mice.

Both UTP and ATP activate target cells by activating $\mathrm{P} 2 \mathrm{X}$ and $\mathrm{P} 2 \mathrm{Y}$ purinergic receptors and $\mathrm{P} 2 \mathrm{Y}$ seventransmembrane-spanning $\mathrm{G}_{\alpha \mathrm{i}}$-coupled receptors are most important in mediating the responses of these novel BM homing factors [17]. Since both ATP and UTP are released from damaged cells, as seen after myeloablative conditioning 
for transplantation, this explain why they play an important role together with other factors in the homing of transplanted HSPCs (Figure 1).

\section{Future Directions}

Evidence has accumulated that the chemotactic responsiveness of HSPCs to several homing gradients could be modulated by ex vivo manipulations. One potential strategy is taking advantage of the HSPC-priming approach. For instance, the possibility of accelerating or enhancing the homing of HSPCs by ex vivo exposure of cells in the graft to C3a before infusion into the patient is currently being evaluated in an ongoing clinical trial (Masonic Cancer Center, University of Minnesota). Another interesting molecule that should be tested in the clinical setting as a potential priming factor is the cathelicidin LL-37. The advantage of LL-37 is that it is a physiological factor secreted by BM stromal cells, and, as shown in Figure 3, is a more potent priming factor than C3a [20]. Another possible ex vivo manipulation of HSPCs in grafting is exposure to PGE2 in order to upregulate expression of CXCR4 to enhance the homing of transplanted cells [24]. This strategy is also currently being evaluated in clinical trial. Overall priming strategies would be important in these clinical situations when a number of HSPCs to be transplanted are limited as seen, for example, in UCB transplants.

Furthermore, since HSPCs in the plasma of mobilized $\mathrm{PB}$ and umbilical cord blood are exposed to relatively high S1P and C1P levels $(\sim 1 \mu \mathrm{M})$ and the S1P receptors and most likely $\mathrm{C} 1 \mathrm{P}$ ones become internalized $\mathrm{mPB}$-derived HSPCs, in contrast to BM-derived HSPCs, they respond weakly to bioactive lipids gradients (Figure 4). To reestablish expression of these receptors on the surface of HSPCs and their responsiveness to $\mathrm{S} 1 \mathrm{P}$ and $\mathrm{C} 1 \mathrm{P}$ gradients, HSPCs should be exposed to culture medium free of both bioactive lipids before transplantation. Furthermore, since several agonists and inhibitors of $\mathrm{S} 1 \mathrm{P}$ receptors promoting $\left(\mathrm{S}_{1} \mathrm{P}_{1}\right.$ and $\left.\mathrm{S}_{1} \mathrm{P}_{3}\right)$ and inhibiting $\left(\mathrm{S}_{1} \mathrm{P}_{2}\right)$ homing and enzymes involved in synthesis or degradation of S1P and C1P are available $[44,82-84]$, this opens up new possibilities for positively modulating the responsiveness of HSPCs to BM $\mathrm{S} 1 \mathrm{P}$ and $\mathrm{C} 1 \mathrm{P}$ gradients. These tools may lead to more efficient strategies to improve homing of HSPCs, and these approaches are currently being tested in murine models.

Since mPB-derived HSPCs show similar relatively weak responsiveness to ATP and UTP gradients (Figure 4), in order to reestablish their responsiveness to gradients of these extracellular nucleotides, HSPCs should be also probably exposed to culture medium free of these factors before transplantation.

In addition to aforementioned strategies there are also other possibilities to manipulate HSPCs to enhance their homing that were out of scope of this paper. Accordingly, based on observations that the SDF-1 interaction with CXCR4 ${ }^{+}$HSPCs is attenuated by the dipeptidyl-peptidase CD26, inhibition of CD26 on HSPCs could enhance the chemotactic responsiveness to an SDF-1 gradient [7]. Another interesting strategy is modification of adhesion molecules on HSPCs by ex vivo treatment with fucosyltransferase that increases level of fucosylation of these receptors [106]. As it has been demonstrated human HSPCs after blockage of CD26 or after fucosylation of adhesion molecules home and subsequently engraft better on immunodeficient mice [104].

These developments suggest that hematological transplantology can take advantage of basic research into novel chemoattractants and priming mechanisms that facilitate homing of HSPCs and translate these observations into more efficient clinical protocols.

\section{Acknowledgments}

This work is supported by NIH Grant R01 DK074720, the EU Innovative Economy Operational Program POIG.01.01.0200-109/09-01, and the Stella and Henry Hoenig Endowment to MZR.

\section{References}

[1] T. Nagasawa, "A chemokine, SDF-1/PBSF, and its receptor, CXC chemokine receptor 4, as mediators of hematopoiesis," International Journal of Hematology, vol. 72, no. 4, pp. 408411, 2000.

[2] T. Ara, K. Tokoyoda, T. Sugiyama, T. Egawa, K. Kawabata, and T. Nagasawa, "Long-term hematopoietic stem cells require stromal cell-derived factor- 1 for colonizing bone marrow during ontogeny," Immunity, vol. 19, no. 2, pp. 257-267, 2003.

[3] T. Lapidot, A. Dar, and O. Kollet, "How do stem cells find their way home?" Blood, vol. 106, no. 6, pp. 1901-1910, 2005.

[4] T. Lapidot, "Mechanism of human stem cell migration and repopulation of NOD/SCID and B2mnull NOD/SCID mice: the role of SDF-1/CXCR4 interactions," Annals of the New York Academy of Sciences, vol. 938, pp. 83-95, 2001.

[5] Y. Vagima, K. Lapid, O. Kollet et al., "Pathways implicated in stem cell migration: the SDF-1/CXCR4 axis," Methods in Molecular Biology, vol. 750, no. 6, pp. 277-289, 2011.

[6] Q. Ma, D. Jones, and T. A. Springer, "The chemokine receptor CXCR4 is required for the retention of $\mathrm{B}$ lineage and granulocytic precursors within the bone marrow microenvironment," Immunity, vol. 10, no. 4, pp. 463-471, 1999.

[7] K. W. Christopherson, G. Hangoc, C. R. Mantel, and H. E. Broxmeyer, "Modulation of hematopoietic stem cell homing and engraftment by CD26," Science, vol. 305, no. 5686, pp. 1000-1003, 2004.

[8] N. Onai, Y. Y. Zhang, H. Yoneyama, T. Kitamura, S. Ishikawa, and K. Matsushima, "Impairment of lymphopoiesis and myelopoiesis in mice reconstituted with bone marrow-hematopoietic progenitor cells expressing SDF-1-intrakine," Blood, vol. 96, no. 6, pp. 2074-2080, 2000.

[9] C. H. Kim, W. Wu, M. Wysoczynski et al., "Conditioning for hematopoietic transplantation activates the complement cascade and induces a proteolytic environment in bone marrow: a novel role for bioactive lipids and soluble C5bC9 as homing factors," Leukemia, vol. 26, no. 1, pp. 106-116, 2012.

[10] P. Hänel, P. Andréani, and M. H. Gräler, "Erythrocytes store and release sphingosine 1-phosphate in blood," FASEB Journal, vol. 21, no. 4, pp. 1202-1209, 2007.

[11] G. Seitz, A. M. Boehmler, L. Kanz, and R. Möhle, "The role of sphingosine 1-phosphate receptors in the trafficking 
of hematopoietic progenitor cells," Annals of the New York Academy of Sciences, vol. 1044, pp. 84-89, 2005.

[12] M. Z. Ratajczak, H. Lee, M. Wysoczynski et al., "Novel insight into stem cell mobilization-Plasma sphingosine-1-phosphate is a major chemoattractant that directs the egress of hematopoietic stem progenitor cells from the bone marrow and its level in peripheral blood increases during mobilization due to activation of complement cascade/membrane attack complex," Leukemia, vol. 24, no. 5, pp. 976-985, 2010.

[13] M. H. Granado, P. Gangoiti, A. Ouro et al., "Ceramide 1phosphate (C1P) promotes cell migration. Involvement of a specific C1P receptor," Cellular Signalling, vol. 21, no. 3, pp. 405-412, 2009.

[14] L. Arana, P. Gangoiti, A. Ouro, M. Trueba, and A. GámezM $\tilde{u} \mathrm{oz}$, "Ceramide and ceramide 1-phosphate in health and disease," Lipids in Health and Disease, vol. 9, article no. 15, 2010.

[15] R. M. Lemoli, D. Ferrari, M. Fogli et al., "Extracellular nucleotides are potent stimulators of human hematopoietic stem cells in vitro and in vivo," Blood, vol. 104, no. 6, pp. 1662 1670, 2004.

[16] L. Rossi, R. Manfredini, F. Bertolini et al., "The extracellular nucleotide UTP is a potent inducer of hematopoietic stem cell migration," Blood, vol. 109, no. 2, pp. 533-542, 2007.

[17] M. Kronlage, J. Song, L. Sorokin et al., "Autocrine purinergic receptor signaling is essential for macrophage chemotaxis," Science Signaling, vol. 3, no. 132, p. ra55, 2010.

[18] M. Z. Ratajczak, R. Reca, M. Wysoczynski et al., “Transplantation studies in C3-deficient animals reveal a novel role of the third complement component (C3) in engraftment of bone marrow cells," Leukemia, vol. 18, no. 9, pp. 1482-1490, 2004.

[19] H. M. Lee, W. Wu, M. Wysoczynski et al., "Impaired mobilization of hematopoietic stem/progenitor cells in C5deficient mice supports the pivotal involvement of innate immunity in this process and reveals novel promobilization effects of granulocytes," Leukemia, vol. 23, no. 11, pp. 2052 2062, 2009.

[20] W. Wu, C. H. Kim, R. Liu et al., "The bone marrowexpressed antimicrobial cationic peptide LL-37 enhances the responsiveness of hematopoietic stem progenitor cells to an SDF-1 gradient and accelerates their engraftment after transplantation," Leukemia, vol. 26, no. 4, pp. 736-745, 2012.

[21] R. I. Lehrer, "Primate defensins," Nature Reviews Microbiology, vol. 2, no. 9, pp. 727-738, 2004.

[22] P. Goichberg, A. Kalinkovich, N. Borodovsky et al., "cAMPinduced $\mathrm{PKC} \delta$ activation increases functional CXCR4 expression on human $\mathrm{CD} 34^{+}$hematopoietic progenitors," Blood, vol. 107, no. 3, pp. 870-879, 2006.

[23] J. Hoggatt and L. M. Pelus, "Eicosanoid regulation of hematopoiesis and hematopoietic stem and progenitor trafficking," Leukemia, vol. 24, no. 12, pp. 1993-2002, 2010.

[24] J. Hoggatt, P. Singh, J. Sampath, and L. M. Pelus, "Prostaglandin E2 enhances hematopoietic stem cell homing, survival, and proliferation," Blood, vol. 113, no. 22, pp. 5444 5455, 2009.

[25] J. P. Lévesque, F. M. Helwani, and I. G. Winkler, "The endosteal osteoblastic niche and its role in hematopoietic stem cell homing and mobilization," Leukemia, vol. 24, no. 12, pp. 1979-1992, 2010.

[26] M. Z. Ratajczak, "Spotlight series on stem cell mobilization: many hands on the ball, but who is the quarterback," Leukemia, vol. 24, no. 10, pp. 1665-1666, 2010.
[27] M. Z. Ratajczak, C. H. Kim, A. Abdel-Latif et al., "Novel perspective on stem cell and mobilization: review on bioactive lipids as potent chemoattractants and cationic peptides as underappreciated modulators of responsiveness to SDF-1 gradients," Leukemia, vol. 26, no. 1, pp. 63-72, 2012.

[28] M. H. Baron, "Embryonic origins of mammalian hematopoiesis," Experimental Hematology, vol. 31, no. 12, pp. 1160 $1169,2003$.

[29] I. Weissman, V. Papaioannou, and R. Gardner, "Fetal hematopoietic origins of the adult hemolymphoid system," in Differentiation of Normal and Neoplastic Cells, B. Clarkson, P. Mark, and J. Till, Eds., pp. 33-47, Cold Spring Harbor Lab. Press, New York, NY, USA, 1978.

[30] C. T. Lux, M. Yoshimoto, K. McGrath, S. J. Conway, J. Palis, and M. C. Yoder, "All primitive and definitive hematopoietic progenitor cells emerging before E10 in the mouse embryo are products of the yolk sac," Blood, vol. 111, no. 7, pp. 3435$3438,2008$.

[31] L. Adamo, O. Naveiras, P. L. Wenzel et al., "Biomechanical forces promote embryonic haematopoiesis," Nature, vol. 459, no. 7250, pp. 1131-1135, 2009.

[32] M. I. Mascarenhas, A. Parker, E. Dzierzak, and K. Ottersbach, "Identification of novel regulators of hematopoietic stem cell development through refinement of stem cell localization and expression profiling," Blood, vol. 114, no. 21, pp. 46454653, 2009.

[33] I. Godin, J. A. Garcia-Porrero, F. Dieterlen-Lièvre, and A. Cumano, "Stem cell emergence and hemopoietic activity are incompatible in mouse intraembryonic sites," Journal of Experimental Medicine, vol. 190, no. 1, pp. 43-52, 1999.

[34] S. J. Morrison, H. D. Hemmati, A. M. Wandycz, and I. L. Weissman, "The purification and characterization of fetal liver hematopoietic stem cells," Proceedings of the National Academy of Sciences of the United States of America, vol. 92, no. 22, pp. 10302-10306, 1995.

[35] T. Ara, Y. Nakamura, T. Egawa et al., "Impaired colonization of the gonads by primordial germ cells in mice lacking a chemokine, stromal cell-derived factor-1 (SDF-1)," Proceedings of the National Academy of Sciences of the United States of America, vol. 100, no. 9, pp. 5319-5323, 2003.

[36] T. Ara, M. Itoi, K. Kawabata et al., "A role of CXC chemokine ligand 12/stromal cell-derived factor-1/pre-B cell growth stimulating factor and its receptor CXCR4 in fetal and adult T cell development in vivo," Journal of Immunology, vol. 170, no. 9, pp. 4649-4655, 2003.

[37] T. Nagasawa, S. Hirota, K. Tachibana et al., "Defects of Bcell lymphopoiesis and bone-marrow myelopoiesis in mice lacking the CXC chemokine PBSF/SDF-1," Nature, vol. 382, no. 6592, pp. 635-638, 1996.

[38] K. Tachibana, S. Hirota, H. Iizasa et al., "The chemokine receptor CXCR4 is essential for vascularization of the gastrointestinal tract," Nature, vol. 393, no. 6685, pp. 591-594, 1998.

[39] Y. R. Zou, A. H. Kottman, M. Kuroda, I. Taniuchi, and D. R. Littman, "Function of the chemokine receptor CXCR4 in heaematopolesis and in cerebellar development," Nature, vol. 393, no. 6685, pp. 595-599, 1998.

[40] Q. Ma, D. Jones, P. R. Borghesani et al., "Impaired Blymphopoiesis, myelopoiesis, and derailed cerebellar neuron migration in CXCR4- and SDF-1-deficient mice," Proceedings of the National Academy of Sciences of the United States of America, vol. 95, no. 16, pp. 9448-9453, 1998.

[41] A. Foudi, P. Jarrier, Y. Zhang et al., "Reduced retention of radioprotective hematopoietic cells within the bone marrow 
microenvironment in CXCR4 ${ }^{-/-}$chimeric mice," Blood, vol. 107, no. 6, pp. 2243-2251, 2006.

[42] K. Kawabata, M. Ujikawa, T. Egawa et al., "A cell-autonomous requirement for CXCR4 in long-term lymphoid and myeloid reconstitution," Proceedings of the National Academy of Sciences of the United States of America, vol. 96, no. 10, pp. 5663-5667, 1999.

[43] M. P. Rettig, G. Ansstas, and J. F. Dipersio, "Mobilization of hematopoietic stem and progenitor cells using inhibitors of CXCR4 and VLA-4," Leukemia, vol. 26, no. 1, pp. 34-53, 2012.

[44] H. Fyrst and J. D. Saba, "Sphingosine-1-phosphate lyase in development and disease: Sphingolipid metabolism takes flight," Biochimica et Biophysica Acta, vol. 1781, no. 9, pp. 448-458, 2008.

[45] H. Meng and V. M. Lee, "Differential expression of sphingosine-1-phosphate receptors 1-5 in the developing nervous system," Developmental Dynamics, vol. 238, no. 2, pp. 487500, 2009.

[46] Y. Nie, Y. C. Han, and Y. R. Zou, "CXCR4 is required for the quiescence of primitive hematopoietic cells," Journal of Experimental Medicine, vol. 205, no. 4, pp. 777-783, 2008.

[47] A. Peled, V. Grabovsky, L. Habler et al., "The chemokine SDF-1 stimulates integrin-mediated arrest of CD $34^{+}$cells on vascular endothelium under shear flow," Journal of Clinical Investigation, vol. 104, no. 9, pp. 1199-1211, 1999.

[48] J. P. Lévesque, Y. Takamatsu, S. K. Nilsson, D. N. Haylock, and P. J. Simmons, "Vascular cell adhesion molecule-1 (CD106) is cleaved by neutrophil proteases in the bone marrow following hematopoietic progenitor cell mobilization by granulocyte colony-stimulating factor," Blood, vol. 98, no. 5, pp. 1289-1297, 2001.

[49] P. L. Doan and J. P. Chute, "The vascular niche: home for normal and malignant hematopoietic stem cells," Leukemia, vol. 26, no. 1, pp. 54-62, 2012.

[50] L. E. Purton and D. T. Scadden, "The hematopoietic stem cell niche," StemBook, 2008.

[51] T. Sugiyama, H. Kohara, M. Noda, and T. Nagasawa, "Maintenance of the hematopoietic stem cell pool by CXCL12CXCR4 chemokine signaling in bone marrow stromal cell niches," Immunity, vol. 25, no. 6, pp. 977-988, 2006.

[52] S. Méndez-Ferrer, T. V. Michurina, F. Ferraro et al., "Mesenchymal and haematopoietic stem cells form a unique bone marrow niche," Nature, vol. 466, no. 7308, pp. 829-834, 2010.

[53] D. J. Ceradini, A. R. Kulkarni, M. J. Callaghan et al., "Progenitor cell trafficking is regulated by hypoxic gradients through HIF-1 induction of SDF-1," Nature Medicine, vol. 10, no. 8, pp. 858-864, 2004.

[54] G. A. McQuibban, G. S. Butler, J. H. Gong et al., "Matrix metalloproteinase activity inactivates the CXC chemokine stromal cell-derived factor-1," Journal of Biological Chemistry, vol. 276, no. 47, pp. 43503-43508, 2001.

[55] R. Reca, D. Mastellos, M. Majka et al., "Functional receptor for C3a anaphylatoxin is expressed by normal hematopoietic stem/progenitor cells, and C3a enhances their homingrelated responses to SDF-1," Blood, vol. 101, no. 10, pp. 3784 3793, 2003.

[56] M. Z. Ratajczak, C. H. Kim, W. Wojakowski, A. JanowskaWieczorek, M. Kucia, and J. Ratajczak, "Innate immunity as orchestrator of stem cell mobilization," Leukemia, vol. 24, no. 10, pp. 1667-1675, 2010.

[57] J. D. Lambris, D. Ricklin, and B. V. Geisbrecht, "Complement evasion by human pathogens," Nature Reviews Microbiology, vol. 6, no. 2, pp. 132-142, 2008.
[58] J. Ratajczak, R. Reca, M. Kucia et al., "Mobilization studies in mice deficient in either $\mathrm{C} 3$ or $\mathrm{C} 3 \mathrm{a}$ receptor $(\mathrm{C} 3 \mathrm{aR})$ reveal a novel role for complement in retention of hematopoietic stem/ progenitor cells in bone marrow," Blood, vol. 103, no. 6, pp. 2071-2078, 2004.

[59] M. Z. Ratajczak, R. Reca, M. Wysoczynski, J. Yan, and J. Ratajczak, "Modulation of the SDF-1-CXCR4 axis by the third complement component (C3)-Implications for trafficking of CXCR4+ stem cells," Experimental Hematology, vol. 34, no. 8, pp. 986-995, 2006.

[60] M. Wysoczynski, R. Reca, H. Lee, W. Wu, J. Ratajczak, and M. Z. Ratajczak, "Defective engraftment of $\mathrm{C}_{3} \mathrm{aR}^{-/-}$hematopoietic stem progenitor cells shows a novel role of the C3aC3aR axis in bone marrow homing," Leukemia, vol. 23, no. 8, pp. 1455-1461, 2009.

[61] Z. Korade and A. K. Kenworthy, "Lipid rafts, cholesterol, and the brain," Neuropharmacology, vol. 55, no. 8, pp. 1265-1273, 2008.

[62] Y. Gu, M. D. Filippi, J. A. Cancelas et al., "Hematopoietic cell regulation by Rac1 and Rac2 guanosine triphosphatases," Science, vol. 302, no. 5644, pp. 445-449, 2003.

[63] M. D. Filippi, C. E. Harris, J. Meller, Y. Gu, Y. Zheng, and D. A. Williams, "Localization of Rac2 via the $\mathrm{C}$ terminus and aspartic acid 150 specifies superoxide generation, actin polarity and chemotaxis in neutrophils," Nature Immunology, vol. 5, no. 7, pp. 744-751, 2004.

[64] J. A. Cancelas, A. W. Lee, R. Prabhakar, K. F. Stringer, Y. Zheng, and D. A. Williams, "Rac GTPases differentially integrate signals regulating hematopoietic stem cell localization," Nature Medicine, vol. 11, no. 8, pp. 886-891, 2005.

[65] F. C. Yang, S. J. Atkinson, Y. Gu et al., "Rac and Cdc42 GTPases control hematopoietic stem cell shape, adhesion, migration, and mobilization," Proceedings of the National Academy of Sciences of the United States of America, vol. 98, no. 10, pp. 5614-5618, 2001.

[66] J. L. Guan, "Integrins, Rafts, Rac, and Rho," Science, vol. 303, no. 5659, pp. 773-774, 2004.

[67] C. Gómez-Moutón, R. A. Lacalle, E. Mira et al., "Dynamic redistribution of raft domains as an organizing platform for signaling during cell chemotaxis," Journal of Cell Biology, vol. 164, no. 5, pp. 759-768, 2004.

[68] T. Ganz, "Defensins: antimicrobial peptides of innate immunity," Nature Reviews Immunology, vol. 3, no. 9, pp. 710-720, 2003.

[69] C. D. Ciornei, T. Sigurdardóttir, A. Schmidtchen, and M. Bodelsson, "Antimicrobial and chemoattractant activity, lipopolysaccharide neutralization, cytotoxicity, and inhibition by serum of analogs of human cathelicidin LL-37," Antimicrobial Agents and Chemotherapy, vol. 49, no. 7, pp. 2845-2850, 2005.

[70] R. Bucki, K. Leszczyńska, A. Namiot, and W. Sokołowski, "Cathelicidin LL-37: a multitask antimicrobial peptide," Archivum Immunologiae et Therapiae Experimentalis, vol. 58, no. 1, pp. 15-25, 2010.

[71] S. M. Zughaier, P. Svoboda, J. Pohl, D. S. Stephens, and W. M. Shafer, "The human host defense peptide LL-37 interacts with Neisseria meningitidis capsular polysaccharides and inhibits inflammatory mediators release," PLoS One, vol. 5, no. 10, Article ID e13627, 2010.

[72] M. Malmsten and A. Schmidtchen, "Antimicrobial C3abiology, biophysics, and evolution," Advances in Experimental Medicine and Biology, vol. 598, pp. 141-158, 2007.

[73] K. Sugita, K. Kabashima, J. I. Sakabe, R. Yoshiki, H. Tanizaki, and Y. Tokura, "FTY720 regulates bone marrow egress of 
eosinophils and modulates late-phase skin reaction in mice," American Journal of Pathology, vol. 177, no. 4, pp. 1881-1887, 2010.

[74] E. M. Durand and L. I. Zon, "Newly emerging roles for prostaglandin E2 regulation of hematopoiesis and hematopoietic stem cell engraftment," Current Opinion in Hematology, vol. 17, no. 4, pp. 308-312, 2010.

[75] A. Avigdor, P. Goichberg, S. Shivtiel et al., "CD44 and hyaluronic acid cooperate with SDF-1 in the trafficking of human $\mathrm{CD} 4^{+}$stem/progenitor cells to bone marrow," Blood, vol. 103, no. 8, pp. 2981-2989, 2004.

[76] N. Shirvaikar, L. A. Marquez-Curtis, M. Z. Ratajczak, and A. Janowska-Wieczorek, "Hyaluronic acid and thrombin upregulate MT1-MMP through PI3K and Rac-1 signaling and prime the homing-related responses of cord blood hematopoietic stem/progenitor cells," Stem Cells and Development, vol. 20, no. 1, pp. 19-30, 2011.

[77] R. Ohkawa, K. Nakamura, S. Okubo et al., "Plasma sphingosine-1-phosphate measurement in healthy subjects: close correlation with red blood cell parameters," Annals of Clinical Biochemistry, vol. 45, no. 4, pp. 356-363, 2008.

[78] H. Fyrst and J. D. Saba, "An update on sphingosine-1phosphate and other sphingolipid mediators," Nature Chemical Biology, vol. 6, no. 7, pp. 489-497, 2010.

[79] T. Sanchez and T. Hla, "Structural and functional characteristics of S1P receptors," Journal of Cellular Biochemistry, vol. 92, no. 5, pp. 913-922, 2004.

[80] J. Rivera, R. L. Proia, and A. Olivera, "The alliance of sphingosine-1-phosphate and its receptors in immunity," Nature Reviews Immunology, vol. 8, no. 10, pp. 753-763, 2008.

[81] H. Obinata and T. Hla, "Sphingosine 1-phosphate in coagulation and inflammation," Seminars in Immunopathology, vol. 34, no. 1, pp. 73-91, 2012.

[82] D. H. Walter, U. Rochwalsky, J. Reinhold et al., "Sphingosine1-phosphate stimulates the functional capacity of progenitor cells by activation of the CXCR4-dependent signaling pathway via the S1P3 receptor," Arteriosclerosis, Thrombosis, and Vascular Biology, vol. 27, no. 2, pp. 275-282, 2007.

[83] J. Michaud, D. S. Im, and T. Hla, "Inhibitory role of sphingosine 1-phosphate receptor 2 in macrophage recruitment during inflammation," Journal of Immunology, vol. 184, no. 3, pp. 1475-1483, 2010.

[84] M. Matloubian, C. G. Lo, G. Cinamon et al., "Lymphocyte egress from thymus and peripheral lymphoid organs is dependent on S1P receptor 1," Nature, vol. 427, no. 6972, pp. 355-360, 2004.

[85] M. L. Allende, J. L. Dreier, S. Mandala, and R. L. Proia, "Expression of the sphingosine 1-phosphate receptor, S1P1, on T-cells controls thymic emigration," Journal of Biological Chemistry, vol. 279, no. 15, pp. 15396-15401, 2004.

[86] S. R. Schwab and J. G. Cyster, "Finding a way out: lymphocyte egress from lymphoid organs," Nature Immunology, vol. 8, no. 12, pp. 1295-1301, 2007.

[87] J. P. Pereira, J. G. Cyster, and Y. Xu, "A role for S1P and S1P1 in immature-B cell egress from mouse bone marrow," PLoS One, vol. 5, no. 2, Article ID e9277, 2010.

[88] E. E. Donovan, R. Pelanda, and R. M. Torres, "S1P3 confers differential S1P-induced migration by autoreactive and nonautoreactive immature B cells and is required for normal Bcell development," European Journal of Immunology, vol. 40, no. 3, pp. 688-698, 2010.

[89] K. Golan, Y. Vagima, A. Ludin et al., "S1P promotes murine progenitor cell egress and mobilization via S1P1 mediated
ROS signaling and SDF-1 release," Blood, vol. 119, no. 11, pp. 2478-2488, 2012.

[90] A. Boath, C. Graf, E. Lidome, T. Ullrich, P. Nussbaumer, and F. Bornancin, "Regulation and traffic of ceramide 1-phosphate produced by ceramide kinase: comparative analysis to glucosylceramide and sphingomyelin," Journal of Biological Chemistry, vol. 283, no. 13, pp. 8517-8526, 2008.

[91] A. Gómez-Muñoz, J. Y. Kong, B. Salh, and U. P. Steinbrecher, "Ceramide-1-phosphate blocks apoptosis through inhibition of acid sphingomyelinase in macrophages," Journal of Lipid Research, vol. 45, no. 1, pp. 99-105, 2004.

[92] D. N. Brindley, D. English, C. Pilquil, K. Buri, and Z. C. Ling, "Lipid phosphate phosphatases regulate signal transduction through glycerolipids and sphingolipids," Biochimica et Biophysica Acta, vol. 1582, no. 1-3, pp. 33-44, 2002.

[93] V. A. Sciorra and A. J. Morris, "Roles for lipid phosphate phosphatases in regulation of cellular signaling," Biochimica et Biophysica Acta, vol. 1582, no. 1-3, pp. 45-51, 2002.

[94] S. R. Schwab, J. P. Pereira, M. Matloubian, Y. Xu, Y. Huang, and J. G. Cyster, "Immunology: lymphocyte sequestration through S1P lyase inhibition and disruption of S1P gradients," Science, vol. 309, no. 5741, pp. 1735-1739, 2005.

[95] J. Long, P. Darroch, K. F. Wan et al., "Regulation of cell survival by lipid phosphate phosphatases involves the modulation of intracellular phosphatidic acid and sphingosine 1phosphate pools," Biochemical Journal, vol. 391, no. 1, pp. 2532, 2005.

[96] D. Mechtcheriakova, A. Wlachos, J. Sobanov et al., "Sphingosine 1-phosphate phosphatase 2 is induced during inflammatory responses," Cellular Signalling, vol. 19, no. 4, pp. 748760, 2007.

[97] Y. Zhao, S. K. Kalari, P. V. Usatyuk et al., "Intracellular generation of sphingosine 1-phosphate in human lung endothelial cells: Role of lipid phosphate phosphatase-1 and sphingosine kinase," Journal of Biological Chemistry, vol. 282, no. 19, pp. 14165-14177, 2007.

[98] R. Pappu, S. R. Schwab, I. Cornelissen et al., "Promotion of lymphocyte egress into blood and lymph by distinct sources of sphingosine-1-phosphate," Science, vol. 316, no. 5822, pp. 295-298, 2007.

[99] Y. A. Hannun and L. M. Obeid, "Principles of bioactive lipid signalling: lessons from sphingolipids," Nature Reviews Molecular Cell Biology, vol. 9, no. 2, pp. 139-150, 2008.

[100] U. Peest, S. C. Sensken, P. Andréani, P. Hänel, P. P. Van Veldhoven, and M. H. Gräler, "S1P-lyase independent clearance of extracellular sphingosine 1-phosphate after dephosphorylation and cellular uptake," Journal of Cellular Biochemistry, vol. 104, no. 3, pp. 756-772, 2008.

[101] G. Burnstock, B. B. Fredholm, R. A. North, and A. Verkhratsky, "The birth and postnatal development of purinergic signalling," Acta Physiologica, vol. 199, no. 2, pp. 93-147, 2010.

[102] G. Burnstock, "Introductory overview of purinergic signaling," Frontiers in Bioscience, vol. 3, pp. 896-900, 2011.

[103] V. Salvestrini, R. Zini, L. Rossi et al., "Purinergic signaling inhibits human acute myeloblastic leukemia cell proliferation, migration, and engraftment in immunodeficient mice," Blood, vol. 119, no. 1, pp. 217-226, 2012.

[104] L. Xia, J. M. McDaniel, T. Yago, A. Doeden, and R. P. McEver, "Surface fucosylation of human cord blood cells augments binding to P-selectin and E-selectin and enhances engraftment in bone marrow," Blood, vol. 104, no. 10, pp. 3091-3096, 2004. 
[105] H. Rauvala, J. P. Prieels, and J. Finne, "Cell adhesion mediated by a purified fucosyltransferase," Proceedings of the National Academy of Sciences of the United States of America, vol. 80, no. 13, pp. 3991-3995, 1982.

[106] W. H. Peranteau, M. Endo, O. O. Adibe, A. Merchant, P. W. Zoltick, and A. W. Flake, "CD26 inhibition enhances allogeneic donor-cell homing and engraftment after in utero hematopoietic-cell transplantation," Blood, vol. 108, no. 13, pp. 4268-4274, 2006. 


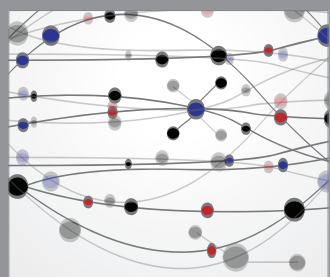

The Scientific World Journal
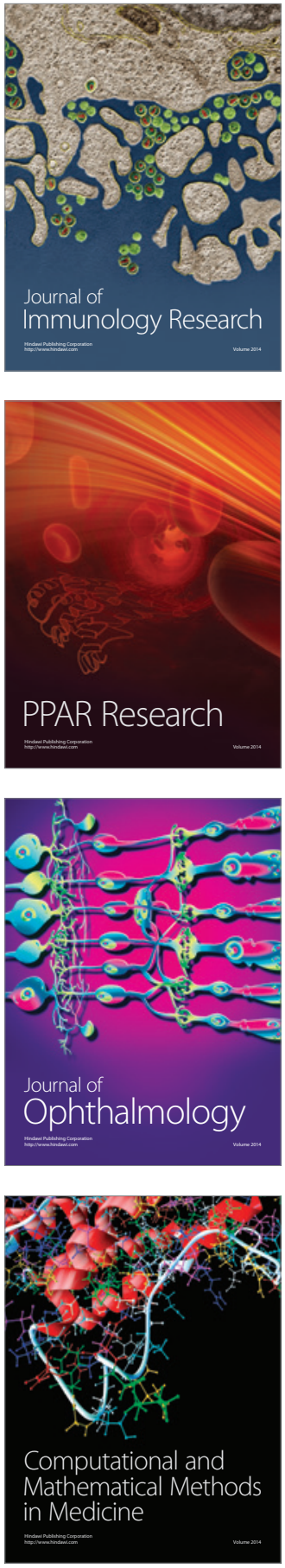

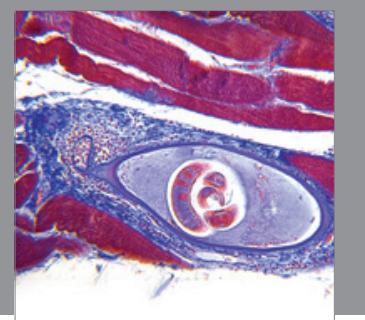

Gastroenterology

Research and Practice
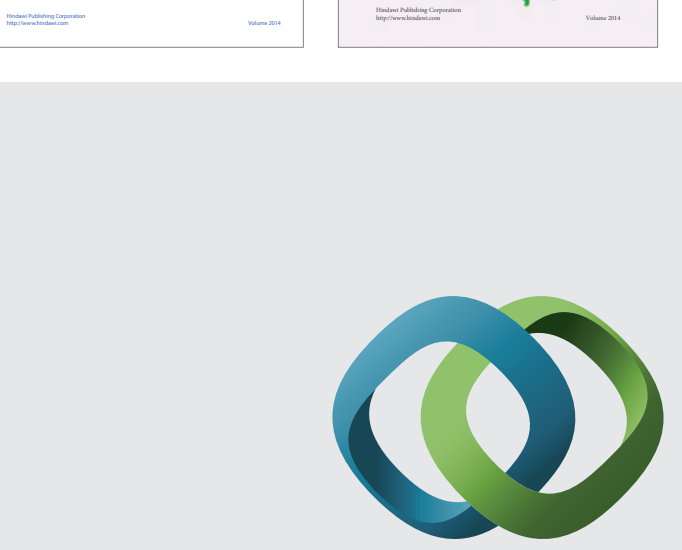

\section{Hindawi}

Submit your manuscripts at

http://www.hindawi.com
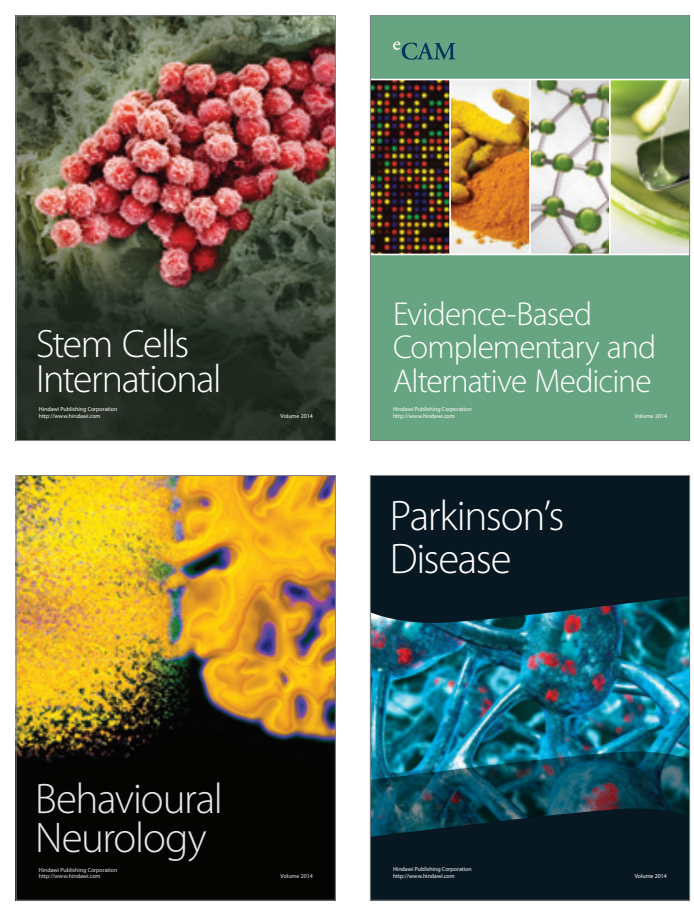

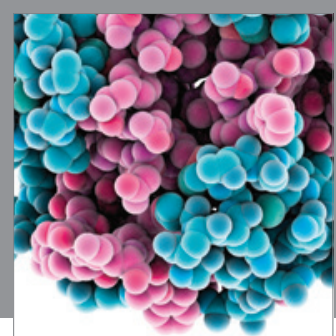

Journal of
Diabetes Research

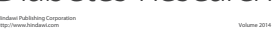

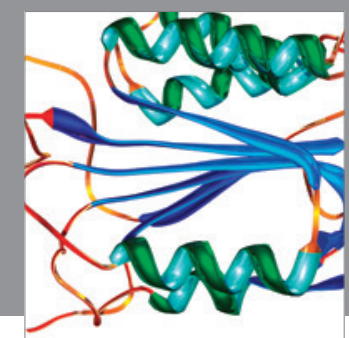

Disease Markers
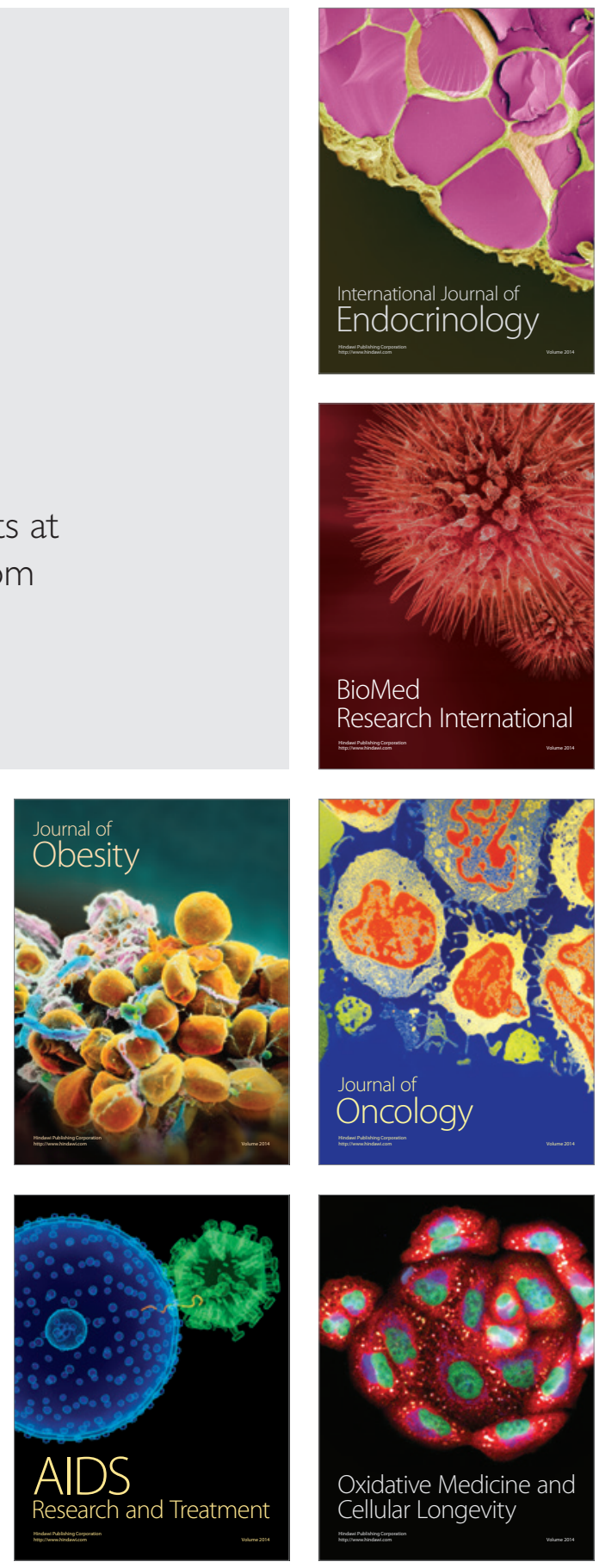